\title{
RELACIÓN DE PUESTOS Y CARGOS DESEMPEÑADOS
}

A lo largo de su trayectoria académica, ha dirigido y participado en proyectos de investigación, de ámbito nacional e internacional, y ha intervenido en numerosos congresos y seminarios de su especialidad, dentro y fuera de España. Resultado de esta trayectoria, tiene reconocidos el máximo número posible de tramos de docencia e investigación (6).

De sus nombramientos, premios y cargos desempeñados, destacan los siguientes:

Premio Extraordinario de Licenciatura en 1968.

Premio «Juan Sebastián Elcano» de investigación otorgado por el CSIC, en 1973.

Profesor Contratado de Geografía en la Universidad de Murcia (1968-1975).

Profesor Adjunto en las Universidades de La Laguna y Valencia (1975-1979).

Profesor Agregado en las Universidades de Granada, Valencia y Alicante (1979-1981).

Catedrático de Geografía de España, en 1981, posteriormente de Análisis Geográfico Regional, en la Universidad de Alicante, hasta su jubilación en 2012.

Miembro correspondiente de la Academia Alfonso X el Sabio de Murcia desde 1977.

Coordinador del Plan de Estudios de la Facultad de Geografía e Historia de la Universidad de la Laguna, en 1976.

Coordinador del Plan de Estudios de la Sección de Geografía e Historia de la Facultad de Filosofía y Letras de Alicante (Universidad de Valencia), en 1978.

Vicedecano de la Facultad de Filosofía y Letras de Alicante (Universidad de Valencia), en 1979. 
Vicerrector de Extensión Universitaria de la Universidad de Alicante desde 1980 a 1985.

Desde 1979, Director del Departamento de Geografía de España de la Universidad de Alicante y, desde 1986 hasta 2006, del Departamento de Análisis Geográfico Regional.

En 1984, medalla de oro de la Universidad de Alicante por la labor realizada desde el Vicerrectorado de Extensión Universitaria en el proceso de puesta en marcha de la Universidad Lucentina.

Secretario de redacción de la revista Investigaciones Geográficas del Instituto Universitario de Geografia, desde 1984 hasta 2005.

Director del Instituto Universitario de Geografía de la Universidad de Alicante (14-05-1985 a 31-05-1986).

Entre 1987 y 1991, Secretario de redacción del Boletín de la Asociación de Geógrafos Españoles (A.G.E.).

Invitación del Geographisches Institut Düsseldorf, en el marco del programa Erasmus, para impartir una conferencia, en 1989, sobre «Aridez y ordenación del espacio agrario en el sureste peninsular».

Entre 1989 y 1991, miembro español de la accion integrada hispano-italiana entre el Instituto de Geografia «G. Morandini» de la Universidad de Padova y el Instituto Universitario de Geografía de la Universidad de Alicante.

En el curso 2006/2007 disfrutó de un periodo sabático concedido por la Universidad de Alicante en el que realizó estancias en varias universidades españolas y en Padova y Udine (Italia), como profesor invitado.

Lección Magistral de Apertura del curso académico 1997-1998 de la Universidad de Alicante, con el título «Aspectos geográficos de la horticultura de ciclo manipulado en España».

Desde 2007, Presidente Titular de la Comisión Nacional de Acreditación de Catedráticos de Universidad de Arte y Humanidades, nombrado por el Consejo de Universidades, a propuesta de la Aneca.

Profesor Emérito de la Universidad de Alicante desde 2012. 


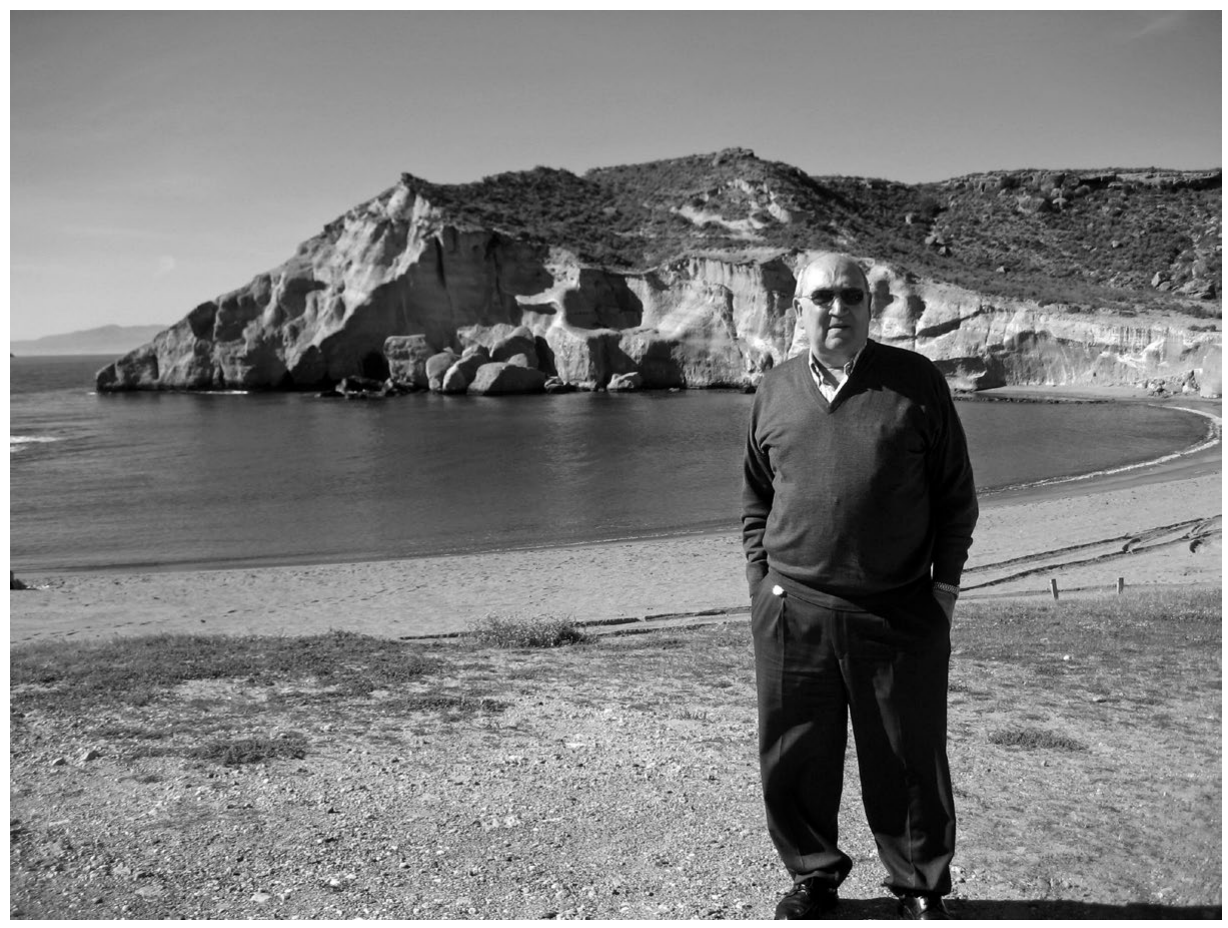

Alfredo Morales Gil (Murcia, 1942) inicia su actividad docente en 1963, como profesor de enseñanza primaria, y tras cursar los estudios de la especialidad de Geografía, comienza su trayectoria académica, como profesor contratado, en la Universidad de Murcia (1968), donde fue discípulo del profesor Vicenç M. ${ }^{\mathrm{a}}$ Rosselló i Verger.

En 1975, por concurso-oposición, obtiene la plaza de Profesor Adjunto en la Universidad de La Laguna y, en 1977, en la de Valencia. En 1979 accede a la plaza de Profesor Agregado, que desempeña en las Universidades de Granada, Valencia y Alicante, donde en 1981 ocupa la plaza de Catedrático de Geografía de España y en la que crea y dirige el Departamento de Análisis Geográfico Regional, para continuar su labor hasta su jubilación, en 2012, cuando es nombrado Profesor Emérito.

Una trayectoria de más de 50 años como docente, 47 de ellos en el magisterio y la investigación universitaria, además de haber dedicado parte de su labor a la gestión académica, y que deja obras de referencia obligada y una impronta por su manera de vivir y enseñar la Geografía. 